\title{
IDENTIDADES NARRATIVAS Y ORGANIZACIONES JUVENILES EN SECTORES POPULARES DE CALI
}

\author{
IDENTIDADES NARRATIVAS E ORGANIZAÇÕES JUVENIS EM SETORES \\ POPULARES DE CALI \\ NARRATIVE IDENTITIES AND YOUTHORGANIZATIONSINCALIPOPULAR \\ SECTORS
}

http://dx.doi.org/10.1590/1807-03102016v28n3p505

\author{
Mauricio Hernán Jiménez Flórez \\ Universidad Libre, Cali y Universidad Cooperativa de Colombia, Cali, Colombia \\ Ana Lucía Sánchez \\ Universidad Cooperativa de Colombia, Cali, Colombia
}

\section{RESUMEN}

Este estudio se inscribe en el construccionismo social con perspectiva narrativa. Su objetivo general es identificar algunos elementos de las identidades narrativas asociadas a la participación en organizaciones juveniles. Es una investigación cualitativa exploratoria, de diseño narrativo y muestreo intencional. Participan once jóvenes de 20 a 26 años que viven en Cali, Colombia. Para recoger los datos se emplean entrevistas semiestructuradas y grupos de discusión. Se realizan análisis textuales y categoriales mediante el software ATLAS. Ti 7.0. Los resultados de la categoría Autoconcepción muestran la continua negociación de la imagen de sí y la creación de un lugar de reconocimiento en el contexto sociocultural. La categoría Proyecto de vida sugiere la calle y la música como espacios semióticos donde se crean objetivos vitales en el contexto de relaciones cotidianas. Como conclusión, se puede afirmar que los relatos son contextualizados pero reflejan cómo los jóvenes re-crean y subvierten sus realidades sociopolíticas.

Palabras clave: identidades narrativas; jóvenes; autoconcepción; proyecto de vida.

\section{RESUMO}

Este estudo inscreve-se no construccionismo social com perspectiva narrativa. Seu objetivo geral é identificar alguns elementos das identidades narrativas relacionadas à participação e organizações juvenis. É uma pesquisa qualitativa exploratória, de desenho narrativo e amostragem intencional. Participam onze jovens de 20 a 26 anos que moram em Cali, Colômbia. Para recolher os dados utilizam-se entrevistas semiestruturadas e grupos de discussão. Realizam-se análises textuais e categoriais por meio do software ATLAS. Ti 7.0. Os resultados da categoria autoconcepção mostram a continua negociação da imagem de si e a criação de um lugar de reconhecimento no contexto sociocultural. A categoria projeto de vida sugere a rua e a música como espaços semióticos onde criam-se objetivos vitais no contexto das relações cotidianas. Em conclusão, pode-se afirmar que os relatos são contextualizados porém refletem como os jovens recriam e subvertem suas realidades sociopolíticas.

Palavras-chave: identidades narrativas; jovens; autoconcepção; projeto de vida.

\begin{abstract}
This study falls within social constructionism from a narrative perspective. Its overall objective is to identify some elements of narrative identities associated with participation in youth organizations. It is a narrative design, purposive sampling, exploratory qualitative research. Eleven young people between 20 and 26 years old living in Cali, Colombia participate in the study. To collect data, semi-structured interviews and discussion groups are used. Textual and categorical analyses are performed by ATLAS.ti 7.0 software. The results of the SelfConception category shows the continuous negotiation of self-image and the creation of a place of recognition in the sociocultural context. The Life Project category suggests street and music as semiotic spaces where life goals are created in the context of everyday relationships. In conclusion, it can be said that stories are contextualized but reflect how young people re-create and subvert their sociopolitical realities.
\end{abstract}

Keywords: narrative identities; young people; self-conception; life project. 


\section{Introducción}

Uno de los participantes en la investigación afirma:

Pues mi sueño era andar en las calles, en pocas palabras, dando bala porque todos los vagos de por ahi [...] eso es lo que uno aprende de esos barrios, pero ahora ya no. Uno ve los amigos con los que creció, los que han muerto, las familias como quedan, las madres como quedan, entonces uno va aprendiendo ¿ya? Y lo que yo quiero ahora es el canto y seguir pa'delante. (Hombre, 23 años, Comuna 18, Cali- Colombia)

¿Por qué la participación activa en una organización juvenil es una experiencia transformadora para los jóvenes de sectores populares? Este artículo pone en juego algunos elementos que permiten reflexionar sobre la relación entre la vinculación a organizaciones juveniles y la construcción narrativa de la identidad de jóvenes de sectores populares. La pregunta problema a responder es: ¿Cuáles son algunos elementos de las identidades narrativas, de once jóvenes con edades entre 20 y 26 años, que pueden asociarse a su participación en organizaciones juveniles ubicadas en la comuna 18 de la ciudad de Cali, Colombia?

Al menos dos argumentos justificaron la investigación. Primero, trascender determinismos sociales tales como que los jóvenes de contextos vulnerables son proclives a la violencia o el delito, postura encontrada en estudios epidemiológicos gubernamentales (Alcaldía de Cali, 2015), en investigaciones académicas (Ballesteros, Contreras, Vargas, Palacio, \& Bonilla, 2002; Torres, 2005) y en programas de intervención social (FUNOF, 2004).

El artículo propone una mirada comprensiva de los jóvenes como productores de arte y cultura (Cuenca, 2016; Garcés \& Medina, 2008; Muñoz, 2007). Sin embargo, no se pretende ocultar o desconocer que una parte de esta población joven de Cali se encuentra vinculada con homicidios, conflicto armado, pandillas, desplazamiento forzado dentro del país e intraurbano, violencia intrafamiliar, ya sea en calidad de víctima o victimario, y las implicaciones que estas situaciones traen a sus procesos de socialización y convivencia. En Cali la tasa de homicidios es alarmante: en los últimos cinco años, periodo 2010 a 2014, se ha presentado un promedio de 1.805 muertes: 2010, 1.825; 2011, $1.843 ; 2012,1.844 ; 2013,1.959$, y en $2014,1.557$. Las estadísticas más recientes muestran que perdieron la vida 2.950 jóvenes durante los años 2005 a 2009, es decir, el $37,4 \%$ del total de homicidios en ese periodo (7.872). También se presentan 485 homicidios de miembros de pandillas, usualmente conformadas por jóvenes (6,16\% del total de homicidios).

Cali está dividida en 21 comunas, constituidas por barrios. La investigación se realiza en la comuna 18. Las muertes violentas en esta comuna ascienden a 690 en el periodo 2000 a 2010 (ver Alcaldía de Cali, 2015). En consecuencia, se hace necesario no la estigmatización y mayor exclusión de los jóvenes, sino acompañamientos que valoren y retomen sus habilidades e intereses.

Un segundo argumento para la realización de esta investigación, remite a la importancia que adquiere este tipo de estudios una vez que se sustenta sobre la base de la descripción que los propios jóvenes hacen de la manera en que comprenden y reconstruiyen la multiplicidad y heterogeneidad de sus construcciones identitarias. Es decir, alejarse de conceptualizaciones maniqueas que los vinculan, por un lado, al consumo de tóxicos, embarazos tempranos y violencia o, por el otro, los exaltan como actores que posibilitan el desarrollo de la sociedad (Escobar, Quintero, Arango, \& Hoyos, 2004). La investigación muestra, en las palabras de los propios jóvenes, la complejidad riqueza $\mathrm{y}$, en muchos casos, el carácter contradictorio de sus construcciones identitarias.

A partir de la revisión de investigaciones sobre juventud se identifican dos tendencias en la comprensión y conceptualización de los jóvenes. En la primera, son entendidos desde visiones de peligrosidad y vulnerabilidad; enfatizándose temáticas de violencia y pandillas (Acero, Escobar-Córdoba, \& Castellanos, 2007; Castillo, 2004; Liebel, 2004) y consumo de sustancias psicoactivas (Cáceres, Salazar, Varela, \& Tovar, 2006; Moral, Rodríguez, \& Ovejero, 2010). En la segunda tendencia, el joven es una fuerza local, un factor renovador y un agente de resistencia; es decir, un sujeto activo, crítico e histórico (Jiménez, 2015; Obando, Jiménez, \& Díaz, 2010; Reguillo, 2000). Aunque estas investigaciones se centran también en poblaciones consideradas vulnerables y excluidas socialmente, hay un énfasis en temas sobre culturas juveniles (Muñoz, 2011; Muñoz \& Marín, 2002; Torres, 2013), participación social (Botero, Ospina, Gómez, \& Ospina, 2008; Valenzuela, 2007) y procesos de organización juvenil (Agudo, Martin, \& Tovar, 2011; Feixa \& Canelles, 2007; Garcés, 2010). En estos estudios, las organizaciones juveniles promueven movilizaciones barriales, lazos de sociabilidad y amistad; los jóvenes son portadores y generadores de experiencias transformadoras de sus contextos relacionales. Por tanto, su participación en organizaciones juveniles se constituye en un escenario donde se negocia quién se es, es decir, su identidad. 
En este sentido, para abordar la relación entre organizaciones juveniles e identidad, se opta por una perspectiva socioconstruccionista, ya que no limita la identidad a un logro singular y aislado de cada joven, sino que la concibe como emergente en medio de relaciones cambiantes, contradictorias y múltiples (Gergen, 2006). Los relatos que construyen los jóvenes sobre sí no son estáticos; se crean y recrean en infinidad de posibilidades relacionales cotidianas; uno de estos espacios relacionales posibles son las organizaciones juveniles. Así y siguiendo a Gergen (2006), no se pretende establecer una visión ontológica y estática sobre la identidad, sino explorar cómo estos jóvenes viven una experiencia de sí en un momento particular y en función del significado que tiene para ellos participar en una organización juvenil.

Cabe señalar que algunos estudios sobre identidad narrativa abordan el tema principalmente desde dos perspectivas: socioconstruccionistas (Burr, 2003; Gergen, 1996, 2006) y socioculturales (Bruner, 1991, 2003), indagando la manera como se narra la experiencia de vida. Diversos autores (Gutiérrez, 2010; Muñoz \& Marín, 2002; Muñoz, 2007; Reguillo, 2000; Revilla, 2001) se han referido al tema de las identidades como resultado del intercambio narrativo con los otros y como formas de constitución de los sujetos. Considerando estas perspectivas e investigaciones se coincide en que la identidad es producto de una construcción social y simbólica, que se sostiene en el tiempo y que posibilita que las personas puedan organizar la experiencia y dotarla de sentido.

Por otro lado, las propuestas metodológicas que se encuentran en estos ejercicios empíricos son de tipo cualitativo, con diversidad de instrumentos que van desde el relato autobiográfico, los grupos de discusión, la entrevista en profundidad hasta la etnografía y la observación participante. Por consiguiente, se puede abordar la identidad desde la perspectiva de los contextos, significados, relaciones y experiencias cotidianas de los jóvenes, vinculados a conceptos como las narrativas (Arfuch, 2007; Bruner, 2003; Gutiérrez, 2010) y la identidad personal (Revilla, 2001).

\section{Algunos elementos conceptuales}

Para realizar esta investigación, se opta por una perspectiva teórica que considera la realidad como una construcción social (Berger \& Luckman, 1979; Bruner, 1991; Burr, 2003; Gergen, 1996, 2006; Ibáñez, 1987; White, 1992; White \& Epston, 1993). Las formas y contenidos que se otorgan a "lo otro" no están dados en la realidad objetiva exterior, sino que se construyen en un contexto particular y a través de relaciones e interacciones puntuales con un otro. La mente y la sociedad no existen separadamente y no hablan en forma independiente (Gergen, 2008). El construccionismo social conlleva el paso de un realismo a un relativismo ontológico (Lincoln, Lynham, \& Guba, 2011). En consecuencia, se considera que los jóvenes construyen relatos sobre sí no individualistas ni esencialistas, sino situados en contextos socioculturales y relacionales particulares.

La construcción social de la realidad puede adoptar la forma de una narración (Bruner, 2003, 2004; Gergen, 1996; Miller, Fung, \& Koven, 2007). Así, se considera legítimo comprender la cultura y las personas por medio de sus prácticas narrativas. Para Bruner (2003) "La narrativa es el relato de proyectos humanos que han fracasado, de expectativas desvanecidas. Nos ofrece el modo de domeñar el error y la sorpresa" (p. 52). El drama humano, con sus contradicciones y vicisitudes, se organiza en forma de relatos que se cuentan y nos contamos para dar orden a la experiencia. La palabra de los jóvenes muestra cómo elaboran explicaciones con sentido sobre sí, y cómo las organizaciones juveniles ocupan un lugar en sus relatos de vida.

Desde esta perspectiva narrativa se enmarca la comprensión de la identidad: ¿Quién soy? La pregunta por la identidad adquiere un lugar fundamental a partir del contexto de la modernidad (Erikson, 1972; Ricoeur, 1996; Taylor, 1997). Para Bauman (2003) “el 'problema moderno de la identidad' era cómo construirla y mantenerla sólida y estable; el 'problema posmoderno de la identidad' es en lo fundamental cómo evitar la fijación y mantener vigentes las opciones" ( $p$. 40). A nivel teórico (epistémico), la identidad escapa a visiones esencialistas, pero su comprensión desde el nivel de la cotidianidad (doxa) es la de ser un elemento que en el fondo brinda una sensación de continuidad y coherencia a las historias de los individuos. Es así como los relatos de los jóvenes se caracterizan por presentar un hilo conductor sobre sí en medio de una profunda riqueza, diversidad y complejidad de sentidos.

Bruner (2003) afirma que "creamos y recreamos la identidad mediante la narrativa, que el Yo es un producto de nuestros relatos" (p. 122). Quién soy y quién es el Otro se puede rastrear en la palabra de los jóvenes. El relato pone en palabras la experiencia, crea su realidad y permite que otros accedan a negociar su significado (Bruner, 2004; Ricoeur, 1996, 1999; Shotter \& Gergen, 1989). La cultura brinda un marco de sentido para estos relatos, que pueden adoptar los más diversos significados; "la cultura es a su vez dialéctica, llena de narraciones alternativas de qué es el Yo, o qué podría ser. Y las historias que contamos para crearnos a noso- 
tros mismos reflejan esa dialéctica" (Bruner, 2003, p. 124). Tan importante es la cultura como el otro en la elaboración de los relatos de sí. Como bien lo recogen las palabras del poeta John Donne (2012) "No preguntes por quién doblan las campanas, doblan por ti".

Es posible acercarse a la identidad narrativa de los jóvenes a través de la escucha atenta de sus relatos, en este caso, las historias que construyen sobre sí en función de su participación en organizaciones juveniles. Es de aclarar que estas organizaciones no son el único espacio donde interactúan los jóvenes, pero las relaciones que establecen en función de su participación en ellas (con otros, ya sean jóvenes o no) inciden en los relatos que crean y recrean constantemente sobre sí y, en este sentido, en la respuesta posible que dan a la pregunta por la identidad, por quiénes son.

En la investigación, la identidad narrativa se delimita a través de dos categorías: Autoconcepción y Proyecto de vida. En primer lugar, la categoría Autoconcepción se define "no como una estructura cognitiva privada y personal del individuo sino como un discurso acerca del yo: la representación de los lenguajes disponibles en la esfera pública" (Gergen, 1996, p. 163). Mediante esta categoría se busca realizar una reconstrucción de los elementos vinculados a la idea de yo, que los jóvenes consideran están relacionados con su participación en organizaciones juveniles. En segundo lugar, la categoría Proyecto de vida "integra las direcciones y modos de acción fundamentales de la persona en el amplio contexto de su determinación por las relaciones entre la sociedad y el individuo" (D'Angelo, 2000, p. 271). Esta categoría explora los objetivos vitales que trazan los jóvenes (D'Angelo, 1998), y permite no solo explorar el sentido que le atribuyen a la vida, sino también su articulación con el contexto social.

La identidad narrativa se explora en personas de 20 a 26 años, considerados ciudadanos jóvenes desde el marco legal colombiano (ver Ley n. 375/1997). Si bien existe en ciencias sociales una tendencia a ordenar la diversidad de expresiones juveniles en categorías que las constriñen, en esta investigación (siguiendo la perspectiva del construccionismo social) se acoge el supuesto de que no existe una forma única de ser joven. Al respecto, Muñoz (2007) plantea que "La resistencia frente a la homogénesis es palpable en los procesos de construcción de subjetividades juveniles contemporáneas: cada vez es más difícil sostener que existe 'el joven' o 'una forma de ser joven'" (p. 24). Por tanto se considera pertinente no encasillar a los jóvenes en una categoría (como podrían ser las de jóvenes bailarines, jóvenes salseros, jóvenes raperos, entre otras), sino indagar las realidades tal y como son construidas por ellos, explorando la multiplicidad de sentidos que emergen en sus relatos.

Una característica fundamental de estos jóvenes es que participan en organizaciones juveniles. Garcés (2010) considera que aunque los colectivos $\mathrm{u}$ organizaciones juveniles se constituyen desde relaciones horizontales y redes informales, cuentan con formas de organización estructurada en las que se establecen objetivos, actividades y funciones específicos. Por lo general, estas organizaciones o colectivos organizan sus proyectos y acciones desde la cultura, el arte y la estética, como modos de participación política y de resistencia. En palabras de Garcés (2010), "hacen de la música, la danza, la comparsa, el graffiti y el esténcil medios de divulgación de la divergencia política, con acciones directas de alto impacto en el espacio público" (pp. 69-70). De hecho, los jóvenes que participan en la investigación hacen parte de un grupo de rap y una escuela de baile.

Las organizaciones juveniles se consideran espacios privilegiados donde se establecen relaciones significativas con otros en la medida en que invierten voluntariamente su tiempo, esfuerzo e incluso dinero para mantenerlas. Así, estas organizaciones se muestran como espacios valiosos para los jóvenes que las integran, y de esta manera representan un camino legítimo para explorar el significado que ocupan para su identidad narrativa.

\section{Método}

\section{Participantes}

El criterio de selección de los participantes $\mathrm{y}$ de las organizaciones juveniles fue intencional (Denzin \& Lincoln, 2011). Se trabaja con dos organizaciones juveniles con más de tres años de existencia reconocida por la comunidad y por los investigadores: Prisioneros de Esperanza (Grupo de Rap, cinco jóvenes) y Fundación Jóvenes en acción por ti Colombia (Organización de Gestión Social y Comunitaria: enseñanza de baile-salsa, seis jóvenes). Estas organizaciones son colectivos con una estructura horizontal, surgieron por iniciativa exclusiva de los jóvenes sin la presencia de adultos. Se orientan al desarrollo de actividades artísticas, lúdicas y comunitarias con la intención política de ser un espacio alternativo a dinámicas de exclusión y violencia.

Se presentan a la convocatoria de dichas organizaciones 14 jóvenes, todos hombres, que debían cumplir con los siguientes criterios de inclusión: vivir en la Comuna 18 de la ciudad de Cali, ser considerados 
jóvenes (14 a 28 años según las leyes colombianas) $\mathrm{y}$ estar vinculado activamente a las actividades cotidianas de su organización. El número definitivo de participantes (once) se constituye mediante proceso de saturación de datos (Denzin, 1978). Los jóvenes vinculados fueron reconocidos como sujetos activos, participativos y con un saber fundamental para la investigación.

\section{Tipo de investigación}

Se opta por una perspectiva cualitativa exploratoria, que permite profundizar críticamente en la comprensión de las particularidades identitarias que se encuentran en las narrativas de los participantes (Denzin \& Lincoln, 2011). Es decir, se realiza una exploración hermenéutica de los elementos identitarios que surgen en los relatos de los jóvenes cuando éstos están asociados a su participación en organizaciones juveniles.

\section{Diseño}

Se opta por un diseño narrativo que posibilita acercarse a los jóvenes participantes como narradores, con relatos que hablan sobre sí, sobre quiénes son. Se concentra en analizar las narraciones como lugar donde se puede explorar la emergencia de elementos sociales y culturales en la vida de las personas (Elliott, 2005). En este sentido, las entrevistas y grupos de discusión son considerados espacios donde se crean, recrean y negocian relatos con sentido sobre quiénes son como jóvenes vinculados a organizaciones juveniles. La identidad toma forma en las relaciones que se entablan con otros y emerge mediada por el lenguaje. Las historias permiten acceder al campo de las versiones que sobre sí mismos construyen los jóvenes, así como al sentido atribuido a la vida que posibilita su organización y transformación (Arfuch, 2007; Ricoeur, 2004).

\section{Producción y análisis de los datos}

Las técnicas de recolección empleadas fueron el grupo de discusión y la entrevista semiestructurada. Los instrumentos (Guía de preguntas orientadoras y Guía de entrevista semiestructurada) fueron revisados y ajustados por dos expertos en investigación cualitativa en psicología.

Los Grupos de discusión consistieron en una conversación grupal en torno a las experiencias de los jóvenes frente a su participación en organizaciones juveniles, a partir de tres categorías inductivas: referentes identitarios que emergen en función de las organizaciones juveniles, relaciones significativas que se han establecido con pares y relaciones significativas que se han establecido con otros. Los grupos de discusión fueron abiertos, de carácter dinámico y dialógico (Ibáñez, 2003) dado que los participantes (incluyendo a los autores del artículo) escuchan y responden según las preguntas, afirmaciones y opiniones que los demás participantes aportan, creando una situación que va más allá de la mera realización de preguntas preestablecidas.

La segunda técnica que se aplicó fue la entrevista semiestructurada, que se entiende como una situación dialéctica mediante la cual se crean dialógicamente realidades (Arfuch, 2007; Elliott, 2005). Las entrevistas semiestructuradas individuales permiten complementar la información obtenida en los grupos de discusión, así como profundizar en elementos emergentes. Las categorías que orientan las entrevistas semiestructuradas son: Autoconcepción, Proyecto de vida, Sujeto político, Relaciones con pares y Relaciones con otros. Cuando se considera necesario se realiza una segunda sesión, que permita recoger información suficiente para responder a las categorías establecidas.

El Grupo de discusión y las entrevistas semiestructuradas se realizan en la comuna 18 , se registran en audio y video y se transcriben fielmente. El programa ATLAS. ti 7.0 se emplea para sistematizar y analizar los datos en forma cualitativa. Se realiza una lectura crítica desde categorías inductivas y emergentes a partir de los datos (Coffey \& Atkinson, 2003).

El primer nivel de análisis textual: se realizan varias lecturas de las transcripciones para lograr una familiarización con sus contenidos. Luego se hace una segmentación de los textos orientada a obtener fragmentos con sentido y significativos a la luz de las categorías inductivas y emergentes de los instrumentos, así se llega a una Unidad Hermenéutica compuesta por 336 citas. Un segundo nivel conceptual: una lectura sistemática de las citas consiste en buscar patrones y regularidades. Se crean definiciones para los códigos y familias de códigos con el fin de facilitar la inclusión y exclusión de fragmentos. Finalmente, se agrupan y establecen relaciones entre citas, lo que se ve reflejado en la creación de 146 Códigos y 5 Familias de Códigos. Por cuestiones de espacio, este artículo sólo presenta los resultados obtenidos en las categorías: Autoconcepción y Proyecto de vida.

\section{Procedimiento}

$\mathrm{Si}$ bien se pueden establecer fases, la investigación tuvo un diseño flexible acorde con su 
postura cualitativa (Coffey \& Atkinson, 2003). Fase I: Reconocimiento de las organizaciones juveniles del sector de la comuna 18 con trayectoria reconocida de al menos 3 años, contacto inicial con los jóvenes e invitación a participar. Fase II: Creación, evaluación y aplicación de instrumentos para construcción de los datos. Fase III: Construcción de los datos mediante la realización de grupos de discusión y entrevistas semiestructuradas. Fase IV: Sistematización y análisis a través de transcripciones fieles, e interpretación por medio de la creación de citas, códigos, familias y memos en Unidad Hermenéutica. Fase V: Establecimiento de relaciones entre las voces de los jóvenes y la voces de la literatura para generar un tercer discurso más informado. Fase V: Elaboración de informe de investigación y socialización de los resultados a los jóvenes participantes y la comunidad.

\section{Resultados}

Se identificaron cuatro elementos identitarios que emergen de los relatos de los jóvenes. Los relatos que construyen para responder a la pregunta por quiénes son, estrechamente vinculadas a su participación en organizaciones juveniles, permitieron identificar los siguientes elementos identitarios: Las imágenes, Ser para el otro, La calle y La música. Cada fragmento seleccionado del discurso de los jóvenes representa tendencias encontradas en los datos.

\section{Autoconcepción: las imágenes}

Para estos jóvenes, estar vinculados a organizaciones juveniles implica un escenario de conflicto en la construcción de su autoconcepción. En algunos casos, la imagen que el otro regresa es de valoración positiva por la participación en las organizaciones juveniles; en palabras de uno de ellos: "ahorita no, pues ha cambiado mucho porque ha influido mucho en mi vida o sea ya uno comienza a conocer muchas personas. Las personas dicen: este muchacho pertenece a alguna agrupación, mira que no está en los vicios" (DP6:021, ES, Diego-22) (Convenciones: DP6 significa Documento Primario seis de la Unidad Hermenéutica de Atlas ti; 021 es el número de línea del DP; ES siglas para Entrevista Semiestructurada o GD para Grupo de Discusión según sea el caso, Diego es el seudónimo para el participante, 22 su Edad).

Elementos como los que se exponen en el párrafo anterior son articulados por los jóvenes a su identidad. Sin embargo, el otro también puede poner en tela de juicio la autoconcepción: “...te explico que hay muchas personas que dicen que el rap es de marihuaneros, que sí que hay personas que llegan y mantienen fumando marihuana y tal cosa y eso es lo que influencia a esos grupos" (DP3:117, ES, Didier-22), afirma uno de los jóvenes que integra una organización juvenil que gira en torno a la música rap. Este estereotipo violenta la forma particular como cada joven se posiciona dentro de estas organizaciones.

La autoconcepción se mueve en una constante y compleja negociación mediada por los otros. Los jóvenes no solo negocian su autoconcepción, sino también quién es el otro. Este significado atribuido al otro afecta el tipo de relaciones que se establecen; así lo menciona un joven que antes integraba una pandilla: "También con los vigilantes y con los policías, hubo un policía que me dijo algo que no me gustó y ijum!... ya me dicen algo y yo, umm, ahora me doy el tiempo de escuchar" (DP10:108, GD, Breiner-23). El otro puede empezar a considerarse un interlocutor válido, alguien con quien se puede entablar una relación mediada por la cordialidad y el respeto. De esta forma vemos que las imágenes que los jóvenes manejan de sí y de los otros tienen lugar en las relaciones que establecen. Así, la identidad se muestra como un proceso conflictivo, que moviliza las interacciones e imágenes que se tienen de sí mismos y de los otros.

\section{Ser para el Otro}

Las organizaciones en las que participan los jóvenes tienen en común la intención de ayudar a otros jóvenes a salir de dinámicas de exclusión y violencia; es decir, estos jóvenes se ubican en un lugar de ayuda a otros jóvenes de sectores populares. Esta característica tiene al menos dos implicaciones para sus autoconcepciones. En primer lugar, genera un espacio de sentido, un norte para la cotidianidad de vida de los jóvenes. Por ejemplo, algunos dedican tiempo y esfuerzo para dar a otros jóvenes un mensaje mediante la enseñanza del baile; no es solo aprender a bailar, sino formar en aspectos como la disciplina, el trabajo en equipo, la constancia. Otros jóvenes lo hacen mediante los sentidos que ponen en juego en las letras de sus canciones de rap:

entonces al dar un mensaje uno piensa en lo que era antes, ¿si pilla? entonces uno se mantenía en las calles por allí vagueando, Uno en el rap da ese mensaje, que uno tiene que seguir para delante y luchar por lo que uno tiene, no andar en las calles fumando vicio ni por aquí, ni para arriba ni para abajo, ¿sí pilla?. (DP1:049, ES, Juán-26)

Los jóvenes albergan la idea de estar en capacidad de poder construir, crear, dar a los otros. La autoconcepción se vincula a la idea de sentirse útiles 
y ser reconocidos como miembros de la comunidad que apuestan a transformar las situaciones injustas de su contexto. En segundo lugar, y en estrecha relación con la idea anterior, creer que se puede dar algo a un otro (que puede ser la sociedad) conlleva una relación de intercambio; al recibir algo, el otro queda en deuda (dar-recibir-devolver). Así lo afirma uno de los jóvenes: "Mantenía mucho en la calle vagueando, me gustaba el juego, las rumbas, todo eso, pero ahora me siento ya bien, he cambiado, ahora yo siento que la sociedad pues quiere que yo esté allí, ¿ya?, en sí eso" (DP4:097, ES, John-26).

Vemos en la cita que el lugar de ayuda a otros jóvenes se invierte; al recibir, el otro se significa en el lugar de alguien que necesita de lo que el joven tiene para dar. Un elemento a través del cual se organiza la autoconcepción es este espacio de sentido que los jóvenes crean en medio de la dinámica dar-recibirdevolver. Las situaciones particulares que dan sentido a las interacciones cotidianas sirven de contexto para la creación de esta dinámica dar-recibir-devolver, que permite a los jóvenes conquistar un lugar en el orden sociocultural así como un referente para su identidad.

Como se ha logrado mostrar, la participación de los jóvenes en organizaciones juveniles incide en cómo construyen y reconstruyen su autoconcepción. Los mismos jóvenes afirman: "Ahora me siento bien y yo me pongo a pensar lo que yo hacía antes a lo que hago ahora y yo digo prefiero lo que estoy haciendo ahora que lo que hacía antes" (DP5:181, ES, Kristian-20). Como aquí se expresa, la cotidianidad de sus vidas cambia mediante las actividades, tareas, objetivos y relaciones que se plantean en el contexto de las organizaciones juveniles. La imagen de sí que el otro regresa en la negociación, la imagen de los otros y las formas de relacionarse con ellos, la valoración positiva que logran y el lugar que crean para sí en el orden social son los aspectos que emergen en los relatos de los jóvenes. Estos elementos se muestran vinculados a como definen y negocian su identidad con otros.

\section{Proyecto de vida: la calle}

La calle es un espacio físico y geográfico en el que los jóvenes de sectores populares - a falta de otro tipo de lugares de orden recreativo, deportivo, educativo - comparten buena parte de su tiempo libre con otros jóvenes. Sin embargo, la calle es también un espacio semiótico donde se negocian y transforman significados. Los jóvenes expresan en sus relatos dos percepciones sobre la calle. Por un lado, se la vive como experiencia peligrosa, de "no futuro", vinculada al consumo de drogas ilícitas, pandillas, homicidios, delincuencia.

No obstante lo señalado en el párrafo anterior, la percepción negativa de la calle no se muestra orientada exclusivamente a factores externos, sino a la dificultad de proponer otras posibilidades de actuación. Uno de los jóvenes afirma: "Pues en la mayoría, he cambiado mucho, mantengo pues mantenemos bien atento a la música y ya no salimos casi como salíamos antes, manteníamos mucho en la calle porque no sabíamos qué hacer" (DP8:017, ES, Carlos-21). Así mismo comenta otro joven: "Yo dejé la 'callejería' yo no volví a salir más, mantengo más en el grupo que en la calle" (DP9:015, ES, Pablo-22). De esta forma la calle adquiere el sentido del sin sentido; es un espacio en donde se interactúa con otros, pero esas experiencias parecen no poder ser articuladas a objetivos vitales de los jóvenes, que redunden en proyectos de vida que trasciendan la experiencia del día a día. Por otro lado, y opuesto a lo que se estaba mencionando, la calle adquiere un sentido de esperanza, posibilita el encuentro constructivo con otros jóvenes, acerca a dinámicas propias de los sectores populares de la ciudad (el barrio) y permite la conformación de organizaciones juveniles. En palabras de un joven: "Como uno es joven piensa en estar parado en las calles y no tiene problema en experimentar cosas nuevas, conocer gente, trabajar con niños y también adquirir conocimientos porque uno siempre tiene que ser mejor como persona" (DP2:095, GD, Baltazar-23). Vemos en esta cita que la calle se significa como un lugar de experimentación, de creación de nuevos espacios desde donde es viable la construcción de proyectos de vida alternativos. Estas dos percepciones contradictorias dan cuenta de la riqueza y complejidad de la experiencia humana; dos sentidos opuestos se entretejen en la compleja tarea de diseñar un proyecto de vida viable.

\section{La música}

La música se muestra articulada a los proyectos de vida de algunos de los jóvenes. Se define la música como experiencia que da sentido a las vivencias y relatos de sí y de los otros; tanto los ritos que acompañan sus bailes como las letras de las canciones que componen reflejan posiciones frente al orden social en el que están inmersos sus proyectos de vida. Un joven de la escuela de baile afirma:

Obviamente, como le decía, yo no sabía que era líder hasta que aprendí a bailar, mirar la disciplina, porque eso me permitió formarme. Porque o sea, el ser humano está compuesto por orden, disciplina y voluntad, ¿ya? (Ehh) entonces, eso me permitió a qué, 
a mirar mis potencialidades, a mirar mis cualidades ¿ya? Y me impulsó. O sea a bailar salsa eso me impulsó, entonces (ehh) tomé pues la vocería de ser líder (DP2:108, GD, Kristian-20)

Acerca del rap un joven afirma lo siguiente: "El proyecto mío es seguir en la música, seguir siendo cantautor, o sea, seguir escribiendo, componiendo mis mismas canciones ... eso ya nos marcó para siempre a nosotros, pertenecer siempre a esta cultura" (DP6:040, ES, Diego-22). En este sentido, la música (ya sea bajo la forma de rap o baile) se ubica como propuesta alternativa a las realidades de violencia y vulneración de derechos existentes en los contextos en donde viven los jóvenes. Es necesario precisar que la música es parte de sus vidas; va más allá de la simple ocupación del tiempo libre. La música es una oportunidad para soñar y planear el futuro. Un joven dice: "Sí, porque, o sea, el rap, lo que cantamos nosotros da un mensaje de lo que somos o lo que queremos que sea la vida" (DP7:103, ES, Jairo-21). La música se muestra como un espacio semiótico a partir del cual se construye un relato que ayuda a dar sentido al presente y al futuro, es un espacio de jóvenes que se vincula a la construcción de sus identidades.

Desde su lugar como jóvenes vinculados a organizaciones juveniles, pensar el momento actual $\mathrm{y}$ futuro pasa por tomar una posición frente a su contexto social. Los objetivos vitales no son de orden individualista: el otro tiene un lugar importante, ya sea directa o indirectamente. Las personas, el mundo social, la realidad son el resultado y a la vez el producto de procesos sociales específicos. La calle y la música son núcleos temáticos que organizan las complejas relaciones sobre las que se elaboran los proyectos de vida. En tanto la calle como espacio peligroso, pero a la vez esperanzador, y la música (baile o rap) como espacio donde se presenta una posición sobre el orden social y donde se construye una perspectiva de sí, son los elementos que emergen en los relatos de los jóvenes en función de sus proyectos de vida y, en consecuencia, de la construcción social de sus identidades.

\section{Discusión}

\section{Autoconcepción y reconocimiento}

La autoconcepción es el fruto de las relaciones que establecen los jóvenes con otros en su diario vivir (Gergen, 1996, 2007), y es en la cotidianidad donde se encuentran con las organizaciones juveniles. La autoconcepción se funda en una profunda relación de dependencia y necesidad de la palabra del Otro (Gergen, 1996; Bruner, 2003), es una construcción social. Se negocia constantemente con otros, en interacciones que definen y redefinen el lugar de los jóvenes en la relación y en su contexto.

Se observa en los relatos citados que los jóvenes intentan conquistar permanentemente estabilidad y seguridad en su identidad (o identidades). Sin embargo, la identidad que se presenta en sus relatos se puede entender como una construcción precaria en el sentido de poca o ninguna estabilidad o duración. Esta característica de precariedad es comprensible en la medida en que la identidad está siempre incompleta pues necesita de otro para ser.

En definitiva la identidad narrativa de los jóvenes está enmarcada en una constante lucha por el reconocimiento del otro (Taylor, 1997), es decir, la forma como los jóvenes se ven a sí mismos está mediada y se busca en la mirada de los otros. Mirada que se agudiza con la proliferación de discursos sobre quién o qué es ser joven en las sociedades contemporáneas (Gergen, 2006; Muñoz, 2011). Por tanto, las prácticas y producciones del mundo juvenil no son una realidad universal, por el contrario, se inscriben en un contexto social y cultural específico. En sus relatos los jóvenes expresan como la importancia de las imágenes de sí $\mathrm{y}$ de los otros, hacen parte de su autoconcepción y se transforman fruto de formas particulares de interacción que se configuran en la cotidianidad (Ibáñez, 1987).

En la búsqueda de la identidad mediada por el reconocimiento de sí que se busca y negocia en la mirada del otro, se pueden ver algunos elementos asociados a una dinámica de dar-recibir-devolver (Malinowsky, 1986; Mauss, 2009; Temple, 2003). Los jóvenes se ubican en una relación de reciprocidad con el otro; ocupan el lugar de donantes frente a otros jóvenes. Esta idea de reciprocidad se distingue de una relación de intercambio comercial en cuanto a que no media un interés centrado en un plano económico. En esencia, los jóvenes no buscan en el otro una retribución económica; en sus palabras, esperan un "Dios se lo pague o un Gracias". En este sentido, el elemento de intercambio es el prestigio (Temple, 2003), es decir, la imagen de sí (su autoconcepción) se pone en juego en la relación con otro, es un proceso constante de construcción social. No se está vacío, en la medida en que se puede dar algo a otros.

Otro aspecto que surge en la dinámica darrecibir-devolver, a pesar de no ser solicitado directamente, son los dones que vuelven por estar se inscritos en relaciones de reciprocidad. En este caso, los jóvenes asumen la creencia de ser necesitados por el otro a quien se da algo. La relación de reciprocidad se establece no solo con otros jóvenes, sino también con Un Otro, la sociedad. 
Un segundo elemento identitario identificado en los relatos de los jóvenes es el Ser para el Otro, que se ve en la dinámica dar-recibir-devolver. La identidad como construcción social pasa por haber logrado crear ese espacio de reconocimiento dentro de esa dinámica de valoración positiva por parte del otro, de sentido en la mirada del otro que les permite sentirse parte de su contexto social, así como reconocidos por un Otro y necesitados por sus aportes a sus comunidades.

\section{Experiencias culturales y estéticas de sí}

Los proyectos de vida que emergen en los relatos de los jóvenes se articulan con las particularidades de sus contextos socioculturales y relacionales tales como la calle, siendo La calle el tercer elemento identitario encontrado en los discursos de los jóvenes. El contexto ocupa el lugar de escenario en el que transcurre la vida de los sujetos y en el que se entrelazan los sentidos de sí y de los otros (Cole, 1999). Los objetivos vitales de los jóvenes muestran la articulación de diferentes esferas: los deseos individuales, el contexto histórico y las necesidades colectivas (D'Angelo, 2000), que se conjugan y negocian en formas de ver, ser y sentir la cotidianidad. Desde esa perspectiva, los proyectos de vida responden a objetivos vitales que fueron negociados en medio de las relaciones que promueven las organizaciones juveniles y se ven materializados en la construcción de futuros posibles y alternativos a los usualmente encontrados en sus contextos.

De acuerdo a lo que se ha señalado, las intenciones que subyacen a los relatos sobre los proyectos de vida dejan entrever el deseo por revindicar, fortalecer y transformar las dinámicas y relaciones sociales de exclusión que los rodean todo esto en el marco de un contexto de sentido que emerge como significativo: $\mathrm{La}$ calle. Donde las acciones están orientadas a proponer estrategias que cambien la realidad y posibilidades de actuación de sí y de otros. Los proyectos de vida permiten ver cómo los jóvenes construyen y reconstruyen su identidad al responder a la pregunta por quién se es en forma situada, desde las tramas de sentido de sus contextos socioculturales particulares.

En este orden de ideas, es evidente que el contexto no es un elemento exterior (Gergen, 2008) al joven; contexto y joven no son dos elementos discretos y separados. El contexto condiciona pero no determina los proyectos de vida que se construyen. Un cuarto elemento identitario encontrado en los relatos de estos jóvenes es la música. En ella encuentran un espacio alternativo de encuentro y de creación.

En los contextos en que los jóvenes actúan se tejen acciones y estrategias que les permiten narrar sus historias, pero también subvertir las condiciones que propone el contexto. Las actividades artísticas hacen viables la reorganización y reconstrucción de nuevas narrativas sobre sí y sobre su futuro. En palabras de Bruner (2003), se trata de un espacio que hace posible la verbalización de la experiencia y, por tanto, la toma de una perspectiva sobre sí y sobre lo real. Es decir, las relaciones que facilitan la participación en organizaciones juveniles se constituyen en un escenario para la invención de lo juvenil. Una invención plural y diversa, que está siempre en movimiento pues debe ser negociada y renegociada en las interacciones con la misma comunidad y con las instituciones con las que se establecen puentes para el desarrollo de sus acciones (Muñoz, 2007).

Las organizaciones juveniles son colectivos de jóvenes, que se constituyen alrededor de diferentes prácticas culturales y artísticas. Las dinámicas y ejercicios que aquí se instauran son actos creativos; son organizaciones de "contra-poder" (Fernández, 2000). Las letras de las canciones, las coreografías de baile, la participación en diversas actividades reorganizan la identidad de los jóvenes en la medida en que se constituyen en lugares alternativos para acceder a la experiencia de sí.

A manera de conclusión, se puede afirmar que los cuatro elementos identitarios que emergen en los relatos (Imágenes, Ser para el Otro, La música y La calle) dan cuenta de la existencia de una relación significativa entre la identidad como una construcción narrativa y la participación de jóvenes en organizaciones juveniles. La organización juvenil media algunas de las relaciones en donde se negocian los relatos que crean y re-crean las identidades; se busca infructuosamente conquistar una historia estable y segura sobre sí, pero la dependencia del otro hace que la construcción sea precaria e inestable.

De acuerdo a lo que se ha propuesto en este artículo, describir los significados compartidos y los elementos discursivos que producen los jóvenes en el desarrollo de sus prácticas demanda, además de un posicionamiento de orden ontológico y epistemológico, el reconocimiento de que "las narrativas del sí mismo, siempre cambiantes, son los procesos mediante los cuales continuamente dotamos de sentido al mundo y, por ende, continuamente nos dotamos de sentido a nosotros mismos" (Goolishian \& Anderson, 1994, p. 300). Las interacciones que promueve la organización juvenil también transforman la representación y los modos de relacionarse y dan paso a ejercicios de reflexividad que articulan de manera compleja sueños, objetivos vitales y contexto sociocultural. Los relatos dejan ver la emergencia de 
la identidad como fenómeno situado en un entramado simbólico particular. Sin embargo, los jóvenes recrean sus realidades, construyen modos alternativos de existencia que se orientan a reivindicar y subvertir su presente y el de otros.

\section{Referencias}

Acero, A., Escobar-Córdoba, F., \& Castellanos, G. (2007). Factores de riesgo para violencia y homicidio juvenil. Revista Colombiana de Psiquiatria, 36(1), 78-97.

Agudo, Y., Martin, E., \& Tovar, F. (2011). Capacidades y límites de la acción juvenil: asociacionismo, nuevas tecnologías y música. Revista de estudios de juventud, 95, 9-29.

Alcaldía de Cali. (2015). Cali en Cifras. Observatorio Social. Acceso noviembre 20 de 2015, en http://planeacion.cali. gov.co/Publicaciones/Cali en Cifras/Caliencifras2010.pdf

Arfuch, L. (2007). El espacio biográfico: dilemas de la subjetividad contemporánea. Buenos Aires: FCE.

Ballesteros, P., Contreras, C., Vargas, F., Palacios, S., \& Bonilla, L. (2002). La pandilla juvenil: breve revisión y análisis funcional de un caso. Revista Internacional de Psicología Clínica y de la Salud, 2(2), 335-350.

Bauman, Z. (2003). De peregrino a turista, o una breve historia de la identidad. En S. Hall \& P. Du Gay (Comps.), Cuestiones de identidad cultural (pp. 40-68). Buenos Aires: Amorrortu.

Berger, P. \& Luckman, T. (1979). La construcción social de la realidad. Buenos Aires: Amorrortu.

Botero, P., Ospina, H., Gómez, E., \& Gutiérrez-Ospina, M. I. (2008). Condiciones de participación y formación política de jóvenes colombianos constructores de paz. Magis, Revista Internacional de Investigación en Educación, 1, 81-94.

Bruner, J. (1991). The narrative construction of reality. Critical Inquiry, 18(1), 1-21.

Bruner, J. (2003). La fábrica de historias: derecho, literatura, vida. Buenos Aires: FEC.

Bruner, J. (2004). Life as narrative. Social Research, 71(3), 691-710.

Burr, V. (2003). Social Constructionism. London: Routledge.

Cáceres D, Salazar I, Varela M, \& Tovar J. (2006). Consumo de drogas en jóvenes universitarios y su relación de riesgo y protección con los factores psicosociales. Universitas Psychologica, 5(3), 521-534.

Castillo, B. H. (2004). Pandillas, jóvenes y violencia. Desacatos, 14, 105-126.

Coffey, A. \& Atkinson, P. (2003). Encontrar el sentido a los datos cualitativos. Estrategias complementarias de investigación. Medellín: Editorial Universidad de Antioquia.

Cole, M. (1999). Psicología cultural. Madrid: Morata.

Cuenca, J. (2016). Los jóvenes que viven en barrios populares producen más cultura que violencia. Revista Colombiana de Psicología, 25(1), 141-154.

D’Angelo, O. (1998). Hacia un nuevo concepto de persona social. Revista Cubana de Psicología, 15(2), 147-153.

D’Angelo, O. (2000). Proyecto de vida como categoría básica de interpretación de la identidad individual y social. Revista Cubana de Psicología, 17(3), 270-275.

Denzin, N. (1978). The research act. A theoretical introduction to sociological methods. New York: Library of Congress Cataloging-in-Publication Data.

Denzin, N. \& Lincoln, Y. (2011). The SAGE Handbook of Qualitative Research. Thousand Oaks, CA: Sage.
Donne, J. (2012). Meditaciones en tiempos de crisis. Barcelona: Ariel.

Elliott, J. (2005). Using Narrative in Social Research. Qualitative and quantitative approaches. London: Sage.

Erikson, E. (1972). Young Man Luther. London: Faber \& Faber.

Escobar, M. R., Quintero, F., Arango, A. M., \& Hoyos, D. (2004) Estado del arte del conocimiento producido sobre jóvenes 1985-2003. Bogotá: Programa Presidencial Colombia Joven; Agencia de Cooperación Alemana GTZ; Unicef Colombia.

Feixa, C. \& Canelles, N. (2007). De bandas latinas a asociaciones juveniles: la experiencia de Barcelona. Educação, 1(61), 1128.

Fernández, C. (2000). La afectividad colectiva. México: Taurus. Fundación para la Orientación Familiar - FUNOF. (2004). Desaprendizaje de la Violencia. Travesía: Jóvenes Construyendo Camino. Cali: Alcaldía de Santiago de Cali.

Garcés, A. (2010). De organizaciones a colectivos juveniles: Panorama de la participación política juvenil. Última década, 18(32), 61-83.

Garcés, A. \& Medina, J. (2008). Músicas de resistencia. Hip Hop en Medellín. La trama de la comunicación, 13, 119131.

Gergen, K. (1996). Realidades y relaciones: aproximaciones a la construcción social. Barcelona: Paidós.

Gergen, K. (2006). El yo saturado. Dilemas de identidad en el mundo contemporáneo. Madrid: Paidós.

Gergen, K. (2007). Construccionismo social. Aportes para el debate y la práctica (A. M. Estrada \& S. Diazgranados, Trads. \& Comps.). Bogotá: Universidad de los Andes.

Gergen, K. (2008). On the very idea of social psychology. Social psychology quarterly, 71(4), 331-337.

Goolishian, H. A. \& Anderson, H. (1994). Narrativa y self. Algunos dilemas posmodernos de la psicoterapia. En D. F. Schnitman (Ed.), Nuevos Paradigmas, Cultura y Subjetividad (pp. 293-306). Barcelona: Paidós.

Gutiérrez, M. (2010). Relato autobiográfico y subjetividad: Una construcción narrativa de la identidad personal. Educere, 14(49), 361-370.

Ibáñez, T. (1987). La "mirada" psicosocial "emergente" y su aplicación al estudio de una categoría social como por ejemplo la juventud. Revista de la Facultat de Lletres de la Universitat de Girona, 7, 73-84.

Ibáñez, T. (2003). Más allá de la sociología. El grupo de discusión: técnica y crítica. Siglo XXI: Madrid.

Jiménez, M. (2015). Ser joven en Colombia: subjetividades, nuevas tecnologías y conflicto armado. Entrevista a Germán Muñoz. Revista Latinoamericana de Ciencias Sociales, Niñez y Juventud. 13(1), 437-445.

Liebel, M. (2004). Pandillas juveniles en Centroamérica o la difícil búsqueda de justicia en una sociedad violenta. Desacatos, 14, 85-104.

Lincoln, Y., Lynham, S., \& Guba, E. (2011). Paradigmatic Controversies. Contradictions, and Emerging Confluences, Revisited. En N. K. Denzin \& Y. S. Lincoln (Eds.), The SAGE Handbook of Qualitative Research (pp. 97-128). Thousand Oaks, CA.: Sage.

Ley n. 375, de Julio 04 de 1997. (1997). Por la cual se decreta la ley de juventud y se dictan otras disposiciones. Bogotá: El Congreso de Colombia. Acceso diciembre 02 de 2015, en http://www.mineducacion.gov.co/1621/articles-85935 archivo_pdf.pdf

Malinowsky, B. (1986). Los argonautas del Pacifico Occidental I. Un estudio sobre comercio y aventura entre los indígenas 
de los archipiélagos de la Nueva Guinea melanésica. Barcelona: Península.

Mauss, M. (2009). Ensayo sobre el don. Forma y función del intercambio en las sociedades arcaicas. Madrid: Katz Editores.

Miller, P. J., Fung, H., \& Koven, M. (2007). Narrative reverberations: How participations in narrative practices cocreates personal and cultures. En S. Kitayama y D. Cohen (Eds.), The handbook of cultural psychology (pp. 595-614). New York: The Guilford University Press.

Moral, M., Rodríguez, F., \& Ovejero, A. (2010). Correlatos psicosociales del consumo de sustancias psicoactivas en adolescentes españoles. Salud Pública de México, 52(5), 406-415.

Muñoz, G. (2007). En la música están la memoria, la sabiduría, la fuerza. Revista Colombiana de Sociología, 28, 199-223.

Muñoz, G. (2011). De las culturas juveniles a las ciberculturas del siglo XXI. Educación y Ciudad, 18, 19-32.

Muñoz, G. \& Marín, M. (2002). Secretos mutantes. Música y creación de culturas juveniles. Bogotá: Universidad Central - DIUC; Siglo del hombre editores.

Obando, O., Jiménez, M., \& Díaz, C. (2010). Subjetividades juveniles en contexto de conflicto armado. In O. Obando (Ed.), Psicología Social Crítica. Aportes y aplicaciones (pp. 271-319). Cali: Universidad Del Valle.

Reguillo, R. (2000). Emergencia de las culturas juveniles. Estrategias del desencanto. Buenos Aires: Norma.

Revilla, J. (2001). Los anclajes de la identidad personal. Papers, 63, 103-122.

Ricoeur, P. (1996). Si mismo como otro. Madrid: Siglo Veintiuno. Ricoeur, P. (1999). Historia y narratividad. Barcelona: Paidós.

Ricoeur, P. (2004). Tiempo y narración I. Configuración del tiempo en el relato histórico. Buenos Aires: Siglo Veintiuno.

Shotter, J. \& Gergen, K. (1989). Texts of Identity. London: Sage.

Taylor, C. (1997). Fuentes del yo. La construcción de la identidad moderna. Buenos Aires: Paidós.

Temple, D. (2003). La teoría de la reciprocidad. Tomo I. La reciprocidad y el nacimiento de los valores humanos. La Paz: Padep; GTZ.

Torres, C. (2005). Jóvenes y Violencia. Revista Iberoamericana de Educación, 37, 55-92.
Torres, L. (2013). Organizaciones juveniles: por el camino de las identidades políticas. Eleuthera, 9(2), 156-185.

Valenzuela, K. (2007) Colectivos juveniles: ¿inmadurez política o afirmación de otras políticas posibles? Última Década, 26, $31-52$

White, H. (1992). El contenido de la forma: narrativa, discurso y representación histórica. Barcelona: Paidós.

White, M. \& Epston, D. (1993). Medios narrativos para fines terapéuticos. Barcelona: Paidós.

Agência de desarrollo: Universidad Cooperativa de Colombia, Cali.

Submissão em: 02/12/2015

Revisão em: 25/06/2016

Aceite em: 31/07/2016

Mauricio Hernan Jimenez Florez es psicólogo, magister en Filosofía, Universidad del Valle (Colombia). Actualmente Investigador y Docente de Jornada Completa, Director

Grupo de Investigación y Acción Psicosocial en Violencias, Desastres y Construcción de Paz (PSIDEPAZ), Facultad de Ciencias de la Salud, Programa de Psicología,

Universidad Libre - Seccional Cali. Hasta 2015 Docente de Tiempo Completo e Investigador, Facultad de Psicología, Universidad Cooperativa de Colombia sede Cali. Dirección: Cra. 37a \#3-29, Cali, Colombia. E-mail: mauriciohjf@yahoo.de; mauricio.jimenez@ unilibrecali.edu.co

Ana Lucía Sánchez es psicóloga, estudiante de maestría en Psicología, Universidad del Valle (Colombia), Docente e Investigadora, Facultad de Psicología, Universidad Cooperativa de Colombia - Cali. E-mail: ana.sanchezv@campusucc.edu.co 